\title{
An Assessment of the Knowledge and Practice of Shaken Baby Syndrome Among Care Givers in Paediatrics Unit Chukwuemeka Odumegwu Ojukwu University Teaching Hospital, Awka
}

\author{
Eyisi I. G. ${ }^{1}$, Nwachukwu C. C. ${ }^{1}$, Njelita I. A. ${ }^{1}$, Umeh U. M. ${ }^{1}$, Eyisi C. S. ${ }^{2}$ \& Igbokwe L. N. ${ }^{3}$ \\ ${ }^{1}$ Department of Community Medicine, Faculty of Clinical Medicine, Chukwuemeka Odimegwu Ojukwu \\ University, Nigeria \\ ${ }^{2}$ Department of Medicine, College of Medicine, University of Nigeria Teaching Hospital, Nigeria \\ ${ }^{3}$ Udi General Hospital, Udi, Enugu State, Nigeria
}

Correspondence: Dr. Eyisi I. G., Department of Community Medicine, Faculty of Clinical Medicine, Chukwuemeka Odimegwu Ojukwu University, Nigeria.

\begin{abstract}
Background: Shaken baby syndrome (SBS) is a form of abuse that is characterized by brain injury and predominantly impacts neurological functioning.[1]It is a non-accidental traumatic injury resulting from the violent shaking of an infant or child.[1,2] Other names for this condition include whiplash shaken infant syndrome, abusive head trauma, shaken impact syndrome, whiplash shake syndrome and non-accidental or intentional head injury but shaken baby syndrome is the most widely used and recognized term;[3]

Methods: Frequencies, percentages, tables and Charts was used to analyze obtained responses with the aid of SPSS version 17.0. Chi-square Tests was also conducted.

Results: No statistically significant association was seen between knowledge of shaken baby syndrome and highest level of education $(\mathrm{X} 2=3.536, \mathrm{p}=0.316)$; No statistically significant association was also seen between knowledge of Shaken Baby Syndrome and gender (X20.329, $\mathrm{p}=0.848)$; and there was no statistically significant difference between wrong practices leading to Shaken baby syndrome and marital status $(\mathrm{X} 2=0.353, \mathrm{p}=0.838)$.

Conclusion: The knowledge of Shaken Baby Syndrome was commendable in this study.

DOI: $10.7176 / \mathrm{JHMN} / 67-11$

Publication date:October $31^{\text {st }} 2019$

\section{Introduction}

Shaken baby syndrome (SBS) is a form of abuse that is characterized by brain injury and predominantly impacts neurological functioning. ${ }^{[1]}$ It is a non-accidental traumatic injury resulting from the violent shaking of an infant or child. ${ }^{[1,2]}$ Other names for this condition include whiplash shaken infant syndrome, abusive head trauma, shaken impact syndrome, whiplash shake syndrome and non-accidental or intentional head injury but shaken baby syndrome is the most widely used and recognized term; ${ }^{[3]}$ however, the term is not widely accepted, for example the American Academy of Pediatrics prefer 'abusive head trauma' which is broad and inclusive of all mechanisms of injury. ${ }^{[4]}$ In 1971, Norman Guthkelch a British pediatric neurosurgeon proposed that whiplash injury caused subdural bleeding in infants by tearing the veins in the subdural space. ${ }^{[5,6]}$ The term whiplash shaken infant syndrome was introduced by Dr John Caffey, a pediatric radiologist, in $1973,{ }^{[7]}$ describing a set of symptoms found with little or no external evidence of head trauma, including retinal bleeds and intracranial bleeds with subdural or subarachnoid bleeding or both. ${ }^{[8]}$ Development of computed tomography and magnetic resonance imaging techniques in the 1970 s and 1980 s advanced the ability to diagnose the syndrome. ${ }^{[9]}$

Child abuse is a global problem that presents in the forms of physical abuse, sexual abuse, neglect, and emotional abuse. ${ }^{[10]}$ Children subjected to various form of abuses can develop emotional, cognitive and physical conditions. The magnitude of abuse in children is often underestimated either because the squeal of abuse, or their young age, makes the victims incapable of articulating what happened to them. .11$]$

Injuries from shaken baby syndrome occurs when a child is being held by the torso or the extremities and subjected to violent shaking that results in rapid head movements with acceleration, deceleration and rotational forces, with or without impact. ${ }^{[12]}$ It results in a unique constellation of intracranial, intraocular and skeletal injuries. ${ }^{[12,13]}$. The most common intracranial abnormality detected is subdural hematoma. Children with SBS are often found to have retinal hemorrhage. ${ }^{[11,14,15]}$. Fractures of the ribs or long bone fractures might also be detected. Cervical spine injuries are rarely recorded in cases of SBS. ${ }^{[13,14]}$
\end{abstract}


Playful interaction with an infant, such as bouncing the baby on the lap or tossing the baby up in the air won't cause injuries associated with shaken baby syndrome. Instead, these injuries often happen when someone shakes the baby out of anger or frustration. ${ }^{[14]}$

The victims of SBS are mostly children under 2 years of age, but it can affect children up to 5 years of age. Most cases of shaken baby syndrome occur among infants that are 6 to 8 weeks old, which is when babies tend to cry the most. Infants and children are particularly vulnerable to violent shaking because of their relatively large head and weak cervical musculature. ${ }^{[16,17]}$ These factors together with the incompletely fused sutures and relatively large volumes of cerebrospinal fluid in young children, allow for greater movement within the cranial vault, resulting in potentially severe damage to the incompletely myelinated brain. ${ }^{[16,17]}$ Perceived disruptive behavior such as unwarranted and unremitting crying spells have been suggested as being important precursors of abuse in the form of 'shaking' by significant figures in the child's life. ${ }^{[18]}$

Perpetrators of SBS are often male with the biological father being the most common abuser. ${ }^{[10]}$ It was also suggested that stepfathers or male partners may also be involved in such heinous acts. ${ }^{[10]}$ Female babysitters are also known to be perpetrators of SBS, as well as biological mothers. Overall, the perpetrator was male in $72 \%$ of cases. ${ }^{[10,14]}$ There is speculation that males, due to their greater physical power, are more likely to cause SBS when they 'shake' children. ${ }^{[10]}$ There is also evidence to suggest that individuals who are prone to anger and marked by explosive personality disorder are likely to commit such acts. ${ }^{[18,19]}$

It is important to raise awareness about abusive head trauma among paediatricians and general practitioners in COOUTH. Doctors providing health services to children should be alert to the non-specific symptoms of SBS in order to reach an early diagnosis. The importance of comprehensive history taking and complete physical examination in young children with suspected abusive head injury is vital. ${ }^{[18]}$

The multidisciplinary approach is a key issue in managing such cases in order to rule out medical mimics of abusive head injuries and better safeguard the child. Educational efforts to raise awareness about SBS should be instituted. ${ }^{[18]}$

\section{Statement of Problem}

Shaken baby syndrome (SBS) resulting in head injury is the leading cause of death and the most common cause of long-term disability and permanent damage in physically abused infants and children. ${ }^{[20,21]}$ The available evidence suggests that around 33 percent of severely shaken infants subsequently die as the result of being shaken. ${ }^{[3,10,22]}$ This rate is $6 \%$ to $12 \%$ higher than that for accidental head injuries in a similar age range. ${ }^{[22]}$ The syndrome has an extremely high degree of morbidity with $60 \%$ of survivors having a moderate or greater degree of disability. [14]

In a research carried out by the U.S. Department of health and human services administration for children and families and the National Child Abuse and Neglect Data System in 2000 approximately 1200 children died of neglect or abuse $; 44 \%$ were infants $<1$ year of age. ${ }^{[23]}$ The majority of deaths related to head injuries in children $<$ 2 years old were a result of non-accidental trauma. ${ }^{[2,24]}$ The national center on shaken baby syndrome in Ogden Utah reported that $>500$ SBS cases, either fatal or non-fatal, occurred in the U.S., the District of Columbia, Guam, Puerto Rico, Saipan, and the Virgin Islands from 1994-1998. The response rate in this study was only $42 \%$ (46 out of 113 surveys) and only $46 \%$ of the respondents reported survivors of SBS. ${ }^{[25]}$

The victims of SBS display a wide range of neurological sequelae. ${ }^{[22]}$ These include cognitive and behavioral disturbances, cerebral palsy, blindness, and epilepsy. ${ }^{[3]}$ It is well known that outcomes due to head injury are more severe in abused children compared to injuries resulting from unintentional accidents. ${ }^{[1,26]}$ The functional prognosis of children marked by SBS is likely to be poor. ${ }^{[27]}$ The victim themselves are likely to be rendered incapable of 'complaining'. The very fact that the incident is associated with neurological dysfunction, makes it likely that some residual though subtle impairment is likely to be chronic and have severe consequences in term of quality of life. ${ }^{[27,28]}$

\section{Justification of Study}

Shaken baby syndrome is now recognized as being the main cause of severe traumatic brain injury in infancy. However, the understanding of the impact of this type of abuse on child development remains sketchy. The study on knowledge of shaken baby syndrome among parents or care givers visiting pediatrics unit in COOUTH Awka will improve the awareness, attitude and knowledge of shaken baby syndrome among parents and caregivers. This study would also go a long way in educating parents of hospitalized infants on the prevention of shaken baby syndrome and also measure their comprehension. This study would shed light on the cognitive dysfunctions that are particular to shaken baby syndrome victims once they are school-aged.

\section{Objectives of Study}

General Objectives

Knowledge and practice of shaken baby syndrome among caregivers visiting pediatrics unit in COOUTH Awka. 


\section{Specific Objectives}

1. To determine the knowledge of shaken baby syndrome among caregivers visiting pediatrics unit in COOUTH Awka.

2. To determine the practice of shaken baby syndrome among caregivers visiting pediatrics unit in COOUTH Awka.

\section{Research Questions}

1. Are most caregivers aware of shaken baby syndrome?

2. Whose activities cause this syndrome more between married and single caregivers?

\section{Null Hypothesis}

There is no significant difference in the level of wrong practices that leads to shaken baby syndrome between the activities of married and single caregivers.

\section{Alternate Hypothesis}

There is significant difference in the level of wrong practices that leads to shaken baby syndrome between the activities of married and single caregivers.

\section{Scope of Study}

The scope of this study covers the knowledge and practice of prevention of shaken baby syndrome among caregivers visiting pediatrics unit in Chukwemeka Odumegwu Odukwu University Teaching Hospital Amaku, Awka.

\section{Knowledge of Shaken Baby Syndrome}

Shaken baby syndrome is a common manifestation of non-accidental head injury in infancy. In Germany, there are estimated 100 to 200 cases annually. ${ }^{[29]}$ The characteristic findings are diffuse encephalopathy, subdural and retinal hemorrhage in the absence of an adequate explanation. The mortality can be as high as $30 \%$; and up to $70 \%$ of survivors suffer long-term impairment ${ }^{[29]}$.

Geddes and Plunkett describe shaking a child to "produce whiplash forces that result in subdural and retinal bleeding," forgetting the most important element in this condition: brain injury itself. They elaborate that the theory of shaken baby syndrome rests on some core assumptions, including that "the injury an infant receives from shaking is invariably severe" [30].

This is in conflict with the research of Alexander et al, Ewing-Cobbs et al, Kemp et al, and Jenny et al, who found that $30 \%-40 \%$ of newly diagnosed shaken baby cases had medical evidence of previously undiagnosed head injury. [29-32]

Another study analyzed these obviously non-inflicted injuries and compared them with abusive head injuries in children under 6 years of age. Severe retinal hemorrhages were seen in 5 of the $233(2 \%)$ children in the noninflicted group and in 18 of the $54(33 \%)$ in the abuse group. ${ }^{[33]}$ Retinal pathology from major trauma mimicking shaken baby syndrome is old news. ${ }^{[34,35,36]}$ Its incidence is dramatically lower than that resulting from inflicted head injury and because of the obvious major trauma history it does not present a diagnostic dilemma.

In a study by Plunkett it was found that death from short falls was still exceedingly rare $(18 / 75000=0.02 \%)$.

In a study carried out in the USA, $50 \%$ to $75 \%$ of teenagers and young adults stated they did not know that shaking is dangerous and between $2.6 \%$ and $4.4 \%$ of the parents of children under 2 years of age reported they had shaken their child at least once. ${ }^{[37,38,39]}$ The equivalent figure for parents in Indian city slums was $42 \%$. ${ }^{[38]}$

According to Lazoritz and Palusci, it is estimated that over 250 children die each year in the United States after being subjected to violent shaking. ${ }^{[40,41,42]}$

According to the CDC, $25 \%$ to $30 \%$ of children victims of AHT die, and only $15 \%$ survive without any sequelae. ${ }^{[43]}$ The study by Keenan et al. found that $80 \%$ of child victims of AHT had eye injuries, a much higher percentage than in children who had suffered accidental pediatric head trauma, which ranged from $6 \%$ to $\left.8 \% .{ }^{[4}\right]$

In a study by Sieswerda - Hoogendoorn et al observed that the main neurological manifestations resulting from AHT are: altered state of consciousness (77\%), seizures (43-50\%), vomiting (15\%), and developmental delay $(12 \%) .{ }^{[45]}$ According to the NCSBS, physical signs of strong pressure on the arms or chest are rare. ${ }^{[46]}$

According to Case et al., head injuries correspond to $80 \%$ of fatal injuries resulting from child maltreatment in younger children. ${ }^{[47]}$

In a study performed in Switzerland, only $28.8 \%$ of the victims recovered completely from AHT, whereas $53.3 \%$ had moderate or severe disability as a result of this form of abuse. ${ }^{[48]}$

In a study by Friedman et al. in New Zealand, the total costs during the life of each child victim of AHT is approximately NZ\$ $1,008,344.00$, equivalent to US\$ 796,591.76. ${ }^{[49]}$ In contrast, the costs for the implementation 
of parental education programs range from US\$ $4.50^{[50]}$ to US $\$ 10.00^{[51]}$ per child.

Deyo et al. used a questionnaire to assess the participants' knowledge of AHT before and after the intervention, and observed a significant increase in knowledge of the pattern of crying in the baby's first months of life. ${ }^{[52]}$

In one study, it was reported that $98 \%$ of the mothers remembered the information given about SBS 3-4 months after the video education called "Love Me...Never Shake Me", 94\% knew what to do when they experienced stress and problems related with their babies, $79 \%$ used the pacifying methods they learned and $92 \%$ gave better care to their babies with these methods. ${ }^{[53]}$

In a study conducted in Canada, $80 \%$ of the mothers who were given an education card reported what they thought about this card when they returned home. ${ }^{[54]}$

In the study conducted in Australia, the rate of recall of the education video was $100 \%$, while it was reported that $34 \%$ of the mothers answered as "yes" to the question "Have you thought of the film you watched?"[55]. In our study, the rate of recall of the education film was found to be $46 \%$. When the mothers were asked the question "Have you received education about the harms of shaking?" this rate increased to $87 \%$. This rate was considerably higher, though it was lower compared to the study conducted in Australia and the rate of the mothers of thinking of the film was higher compared to the study conducted in Australia (66\%). ${ }^{[56]}$

In a study conducted with 1826 mothers who had babies aged three months in Holland, $10 \%$ of the mothers reported that they used the methods of shaking or battering to silence their babies. It has been reported that this risk was $2-3$ fold higher in babies who cry extremely and in Turkish people.

The most common exploiters in shaken baby syndrome are men ${ }^{[7,58,59]}$. In different education methods, educating men is also recommended. ${ }^{[57]}$

\section{Practice of Shaken Baby Syndrome}

In recent studies carried out in Scotland, United States, New Zealand and Switzerland, the incidence of AHT has been demonstrated to range from 14.7 to 38.5 cases per 100,000 children, with greater incidence in children younger than 1 year. ${ }^{[60-64]}$

Also in a study conducted by the CDC in Scotland, United States and Switzerland, the incidence in the country was 0.76 fatal cases of AHT per 100,000 children under 4 years of age, increasing to 2.14 when considering only children younger than 1 year. ${ }^{[65]}$

In another study from the World Health Organization (WHO) and from the International Society for Prevention of Child Abuse and Neglect (ISPCAN) demonstrate that in 2002, over 53,000 children younger than 15 years of age died across the world due to situations of abuse. ${ }^{[66]}$ Among the forms of child abuse, it is worth mentioning pediatric abusive head trauma, due to its severity. In the year 2002, it is estimated that 1,400 children died from maltreatment in the United States, ${ }^{[67]}$ and pediatric abusive head trauma accounts for $80 \%$ of these deaths, the leading cause of death for children that are victims of maltreatment. ${ }^{[68]}$

In a study by Theodore and Runyan in North and South Carolina, $2.6 \%$ of parents of children younger than two years reported that they had shaken their children as a way to discipline them. ${ }^{[69]}$

In USA, the rate of the families who use physical violence as a discipline method has been reported to be $4.3 \%$ and the rate of parents (especially mothers) who use shaking as a discipline method in children aged below two years has been reported to be $2.6 \%{ }^{[70]}$.

In another study conducted in USA, no relation was found between the income levels of families and the frequency of shaking in contrast to what is expected. ${ }^{[70]}$ In our study, no relation was found between the income level of the family and the education level of the mother and the frequency of thinking of shaking. Although shaking is used as a discipline method with a higher rate in families with low income levels, the reason that there was no relation between the income level of the parents and the frequency of thinking of shaking in this study similar to the study conducted in USA may be explained with the possibility that these families might have hidden the facts because of fear.

In another study conducted with 3259 mothers who had babies aged below 6 months in Holland, it was reported that $5.6 \%$ of the mothers battered or shaked their babies at least for one time while their babies cried ${ }^{[71]}$.

The study by Vinchon et al. was a prospective study. It was based on a register of traumatic head injury in children aged under 2 years, who were admitted to hospital between May 2001 and February 2009, in a catchment area with a population of about 4 million ${ }^{[72]}$. The material comprised 412 cases, of which 124 were classified as Inflicted Head Injury (IHI) and 288 as Accidental Trauma (AT). In the group with inflicted injury (IHI group), there were 45 confessed cases: 30 by traumatic shaking and 15 in which the perpetrator admitted to other external trauma. In the group with inflicted trauma, 37 out of $45(82 \%)$ had a subdural hematoma, compared with 17 out of 39 $(44 \%)$ in the accidental trauma group; 37 out of $44(84 \%)$ had retinal hemorrhages, compared with 6 out of 35 $(17 \%)$ in the accidental trauma group and 12 out of $45(27 \%)$ had cerebral ischemia, compared with 1 out of 39 (3 percent) in the group with accidental head trauma.

The study by Adamsbaum et al. was a retrospective observational study, comprising 29 confessed cases of traumatic shaking (in which direct trauma to the head was described in 5 cases) and a comparative group of 83 
unconfessed cases. ${ }^{[73]}$

In the group in which traumatic shaking was confessed to (Group A) 24 children (83\%) had retinal hemorrhages. In all cases where the perpetrator had confessed, the shaking was described as violent (100\%) and in some cases $(55 \%)$ the perpetrator admitted to repeated episodes of shaking. No correlation was established between the density of the subdural hematoma and the number of repeated episodes of shaking. In 14 out of 29 cases in Group A there was a detailed description of how the suspect had committed the act. In the other group (Group B) there were children who had been shaken in an attempt at revival, or had suffered accidental injury and some children for whom no explanation of the condition was presented: thus this group cannot be considered an acceptable reference group.

The studies by Vinchon et al. and Adamsbaum et al. both demonstrate that traumatic shaking can cause subdural hematoma and retinal hemorrhages. In the study by Vinchon et al., the group in which traumatic shaking was confessed to comprised a larger proportion of children with subdural hematoma, retinal hemorrhages and cerebral ischemia than the group of children who had been injured in a witnessed accident. Adamsbaum et al. compared a group of children in which the perpetrators had confessed to traumatic shaking, with a group of children in which the suspects had not confessed: this can result in inclusion bias in one or both groups.

In another study done in Brazil, $10 \%$ of mothers were interviewed in a study conducted in Embu, state of São Paulo and they reported having shaken their children younger than two years of age in the last year. ${ }^{[7]}$

In another study conducted with 3345 babies by Reijneveld SA et al in Holland, it was reported that the parents who came from undeveloped countries, who were unemployed or had part-time employment and the parents who thought that their babies cried too much had a higher risk in terms of battering and shaking their babies ${ }^{[75]}$.

In another study with 142 professionals from family health units of a small city in the state of Pernambuco, 60.8\% of the respondents reported having shaken a child or a baby;50.5\% of them declared that they had shaken the child to make him/her go to sleep and $25.7 \%$ to make him/her stop crying. ${ }^{[76]}$

In the group with inflicted trauma, 37 out of $45(82 \%)$ had a subdural hematoma, compared with 17 out of 39 $(44 \%)$ in the accidental trauma group; 37 out of 44 (84\%) had retinal hemorrhages, compared with 6 out of 35 $(17 \%)$ in the accidental trauma group and 12 out of $45(27 \%)$ had cerebral ischemia, compared with 1 out of 39 (3 percent) in the group with accidental head trauma.

In the group in which traumatic shaking was confessed to (Group A) 24 children (83\%) had retinal hemorrhages. In all cases where the perpetrator had confessed, the shaking was described as violent (100\%) and in some cases $(55 \%)$ the perpetrator admitted to repeated episodes of shaking. No correlation was established between the density of the subdural hematoma and the number of repeated episodes of shaking. In 14 out of 29 cases in Group A there was a detailed description of how the suspect had committed the act. In the other group (Group B) there were children who had been shaken in an attempt at revival, or had suffered accidental injury and some children for whom no explanation of the condition was presented: thus this group cannot be considered an acceptable reference group.

The actual aim of SBS prevention programs is to decrease the frequency of SBS. In the program planned by the 'Shaken Baby Syndrome National Center', it was reported that non-accidental head traumas decreased by $47 \%$ in a three-year period in New York with giving information about SBS in the hospital to all parents who had newborn babies. ${ }^{[77,78]}$

In Turkey, the prevalence of SBS is not known. The fact that the effects of SBSPP on the frequency of SBS were not evaluated with long-term follow-up in this study was a limitation of the study. In our country, further studies are needed in this area.

When the mothers were asked the question "Have you thought of shaking your baby?", $9 \%$ of the mothers who received SBS prevention education and 3.5\% of the mothers who did not receive SBS prevention education answered as "yes"; it was observed that the frequency of shaking did not change with SBS prevention program. In the reason that the rate of this answer was lower than expected may be the fact that the mothers might have not confessed and might have hidden this emotion with the awareness that harming their baby is an unacceptable behavior.

In various studies, it has been reported that mothers who report that they "batter or shake" their babies usually have a low education and a low income level. ${ }^{[56,79]}$

\section{Methodology \\ Area of Study}

Chukwuemeka Odumegwu Ojukwu University Teaching Hospital (COOUTH), Awka is a tertiary health care institution located in Awka South L.G.A of Anambra State. COOUTH is in the heart of Awka and is a State Government Health facility under the state ministry of health. It is one of the campuses of Chukwuemeka Odumegwu Ojukwu University, Anambra State.

The institution was formerly a general hospital before it was upgraded to a tertiary institution as the teaching hospital belonging to the State University, Chukwuemeka Odumegwu Ojukwu University. The hospital and its 
annexes since inception have provided specialized and comprehensive medical care to the immediate community and beyond. It is also responsible for undergraduate medical training as well as research.

The hospital runs the following clinics:

1. Children Out-Patient Department

2. General Out-Patient Department

3. Specialist Out-Patient Department

4. Antenatal Clinic

5. Accident and Emergency Clinic

6. Immunization Clinic

7. Anti-Retroviral Therapy Clinic

8. Special Care Baby Clinic

9. Gynecology Clinic

The hospital runs these clinics concurrently during the weekdays with the Accident and Emergency and General Out-patient clinics extending into the weekends. There is also 24hour Medical diagnostic service and a reliable blood bank.

\section{Study Population}

This consists of caregivers visiting COOUTH pediatrics unit and immunization center, Awka.

Caregivers are biological parents/persons assigned to take care of the child.

\section{Inclusion Criteria}

Volunteers were consenting caregivers and parents who visit COOUTH paediatrics unit and immunization center.

\section{Exclusion Criteria}

Non consenting caregivers and those who don't visit COOUTH pediatrics unit and immunization center.

\section{Study Design}

This is a descriptive cross-sectional study.

\section{Sample Size Determination}

Using the fisher's formula for calculating minimum sample size for cross sectional studies

$\mathrm{n} \quad \frac{\mathrm{Z}^{2} \mathrm{P}(1-\mathrm{p})}{\mathrm{D}^{2}}$

\section{Where}

$\mathrm{n}-$ minimum sample size

Z - Standard normal deviate usually 1.96

$\mathrm{P}$ - Prevalence from a previous study by CDC in Scotland and United States ${ }^{[65]}$

D - Margin of error tolerated usually $5 \%=0.05$

Hence $\mathrm{n}=\underline{(1.96)^{2} \mathrm{x} 0.76(1-0.76)}$

$$
(0.05)^{2}
$$

$$
\mathrm{n}=\frac{3.84 \times 0.76 \times 0.24}{0.0025}
$$

$\mathrm{n} \quad=\underline{0.700}$

$$
0.0025
$$

$\mathrm{n}=280$

$$
\text { Then } \mathrm{nf} \quad=\frac{\mathrm{n}}{1+\underline{\mathrm{n}}}
$$

\section{Where \\ nf $=$ Desired sample size when study population $<10,000$ \\ n $\quad=$ Desired sample size when the study population $>10,000$ \\ $\mathbf{N}=$ Estimate of the population size $=250$}


Nf $=280$

$$
1+\frac{(280)}{250}=133
$$

Non response

$$
=\frac{10 \times 133}{100}
$$

$=13.3$

$$
\begin{aligned}
\text { Sample size }=133 & +13 \\
= & 146
\end{aligned}
$$

\section{Sample Method}

Simple systematic sampling was used where every even numbered patient according to order of arrival was interviewed.

\section{Instruments for Data Collection}

A self-administered questionnaire was used and it consists of 3 sections:

Section A: $\quad$ Socio demographic characteristics/Bio-data.

Section B: $\quad$ Knowledge of shaken baby syndrome

Section C: $\quad$ Practice of shaken baby syndrome

\section{Data Analyses}

Questionnaires were checked for errors and omissions at the end of each day. Data was entered into the computer and analyzed using SPSS (statistical package for social science) version 17.0. Data errors were checked and corrected.

The variables obtained were represented in tables and bar charts and was interpreted appropriately.

\section{Ethical Considerations}

Ethical approval was obtained from COOUTH ethical review committee. Informed verbal consent was obtained from research respondents before administration of questionnaires. Participation was made voluntary. All information collected was strictly kept confidential.

\section{Limitations}

1. Time limitation and financial constraints

2. Poor attitude of respondents to the questionnaire

\begin{tabular}{|c|c|c|c|}
\hline Variables & & Frequency $n=146$ & Percentage (\%) \\
\hline \multirow[t]{2}{*}{ Sex } & Male & 46 & $31.5 \%$ \\
\hline & Female & 100 & $68.5 \%$ \\
\hline \multirow[t]{5}{*}{ Age } & $16-25$ & 39 & $26.7 \%$ \\
\hline & $26-35$ & 68 & $46.6 \%$ \\
\hline & $36-45$ & 31 & $21.2 \%$ \\
\hline & $46-55$ & 7 & $4.8 \%$ \\
\hline & $56-65$ & 1 & $0.7 \%$ \\
\hline \multirow[t]{3}{*}{ Marital Status } & Single & 49 & $33.6 \%$ \\
\hline & Married & 85 & $58.2 \%$ \\
\hline & Divorced & 12 & $8.2 \%$ \\
\hline \multirow[t]{5}{*}{ Occupation } & Unemployed & 28 & $19.2 \%$ \\
\hline & Civil servant & 39 & $26.7 \%$ \\
\hline & Trader & 22 & $15.1 \%$ \\
\hline & Self employed & 34 & $23.3 \%$ \\
\hline & Other & 23 & $15.8 \%$ \\
\hline \multirow[t]{4}{*}{ Highest Level of Education } & No formal & 7 & $4.8 \%$ \\
\hline & Primary & 6 & $4.1 \%$ \\
\hline & Secondary & 54 & $37.0 \%$ \\
\hline & Tertiary school & 79 & $54.1 \%$ \\
\hline \multirow[t]{3}{*}{ Religion } & Christian & 137 & $93.8 \%$ \\
\hline & Muslim & 9 & $6.2 \%$ \\
\hline & Other & 0 & $0.0 \%$ \\
\hline
\end{tabular}

3. Lack of formal education posed a barrier in obtaining adequate information.

4. Some respondents were reluctant to participate for which I pleaded with them to exercise patience.

5. Nigerian studies are not adequate on this topic and this limited our discussion of results.

\section{Quantitative Findings}

\section{Table 1: Socio-demographic findings}

A total of 146 caregivers agreed to participate in the study resulting in a response rate of $100 \%$. Female $100(68.5 \%)$ 
participated more than male 46 (31.5\%). Majority of the participants were married 85 (58.2\%) while 79 (54.1\%) had tertiary school as their highest level of education. Other socio-demographic characteristics are as shown in the table.

Table 2: Responses to questions on knowledge of Shaken Baby syndrome

\begin{tabular}{|c|c|c|}
\hline \multicolumn{2}{|l|}{ KNOWLEDGE OF SHAKEN BABY SYNDROME } & Frequency $(\%)$ \\
\hline \multirow[t]{2}{*}{ Do you know about shaken baby syndrome? } & Yes & $107(73.3 \%)$ \\
\hline & No & $39(26.7 \%)$ \\
\hline \multirow[t]{5}{*}{ If yes how did you know? } & Textbooks & $11(9.9 \%)$ \\
\hline & Media & $28(25.2 \%)$ \\
\hline & Internet & $27(24.3 \%)$ \\
\hline & Church & $17(15.3 \%)$ \\
\hline & Other & $28(25.2 \%)$ \\
\hline & Yes & No \\
\hline $\begin{array}{l}\text { Do you know that shaking a baby vigorously can cause serious } \\
\text { harms to the baby? }\end{array}$ & $117(80.1 \%)$ & $29(19.9 \%)$ \\
\hline Do you know a baby can die as a result of severe shaking? & $86(58.9 \%)$ & $60(41.1 \%)$ \\
\hline $\begin{array}{l}\text { Do you know that shaking a baby vigorously can make him } / \text { her } \\
\text { go blind permanently? }\end{array}$ & $55(37.7 \%)$ & $91(62.3 \%)$ \\
\hline $\begin{array}{l}\text { Do you know that shaking a newborn vigorously can impair their } \\
\text { posture? }\end{array}$ & $78(53.4 \%)$ & $68(46.6 \%)$ \\
\hline $\begin{array}{l}\text { Do you know that shaking a newborn vigorously can result to } \\
\text { sleep disorders? }\end{array}$ & $66(45.2 \%)$ & $80(54.8 \%)$ \\
\hline Do you know that shaking a baby can cause bone fractures? & $94(64.4 \%)$ & $52(35.6 \%)$ \\
\hline $\begin{array}{l}\text { Do you know that shaking a baby vigorously can cause } \\
\text { convulsion? }\end{array}$ & $82(56.2 \%)$ & $64(43.8 \%)$ \\
\hline
\end{tabular}

From Table 2, 73.3\% of the participants know about Shaken baby syndrome (SBS) among which $25.2 \%$ got the knowledge from media, $24.3 \%$ from internet and the rest were from Church, textbooks and other means. Other responses on the knowledge of wrong practices leading to shaken baby syndrome are summarized in the table.

Table 3: A cross tabulation showing the result of test of significance between knowledge of Shaken Baby Syndrome and highest level of education using Chi-square

\begin{tabular}{|c|c|c|c|c|c|}
\hline \multirow[b]{2}{*}{ Highest Level of Education } & \multicolumn{2}{|c|}{ Knowledge of Shaken Baby Syndrome } & \multirow[b]{2}{*}{ Total } & \multirow[b]{2}{*}{$\mathbf{X}^{2}$} & \multirow[b]{2}{*}{ P-VALUE } \\
\hline & Not Aware & Aware & & & \\
\hline No formal & $\begin{array}{c}0 \\
0.0 \%\end{array}$ & $\begin{array}{c}7 \\
100 \%\end{array}$ & $\begin{array}{c}7 \\
100.0 \%\end{array}$ & \multirow{5}{*}{3.536} & \multirow{5}{*}{0.316} \\
\hline Primary & $\begin{array}{c}0 \\
0.0 \%\end{array}$ & $\begin{array}{c}6 \\
100 \%\end{array}$ & $\begin{array}{c}6 \\
100.0 \%\end{array}$ & & \\
\hline Secondary & $\begin{array}{c}12 \\
22.2 \%\end{array}$ & $\begin{array}{c}42 \\
40.7 \%\end{array}$ & $\begin{array}{c}54 \\
100.0 \%\end{array}$ & & \\
\hline Tertiary school & $\begin{array}{c}14 \\
17.7 \% \\
\end{array}$ & $\begin{array}{c}65 \\
77.8 \% \\
\end{array}$ & $\begin{array}{c}79 \\
100.0 \% \\
\end{array}$ & & \\
\hline Total & $\begin{array}{c}26 \\
17.8 \%\end{array}$ & $\begin{array}{c}120 \\
82.2 \%\end{array}$ & $\begin{array}{c}146 \\
100.0 \%\end{array}$ & & \\
\hline
\end{tabular}

At a Chi-Square value of 3.536, the p-value is 0.316 and since it is $>0.05$, there is no statistically significant difference between knowledge of Shaken Baby syndrome and highest level of education. 


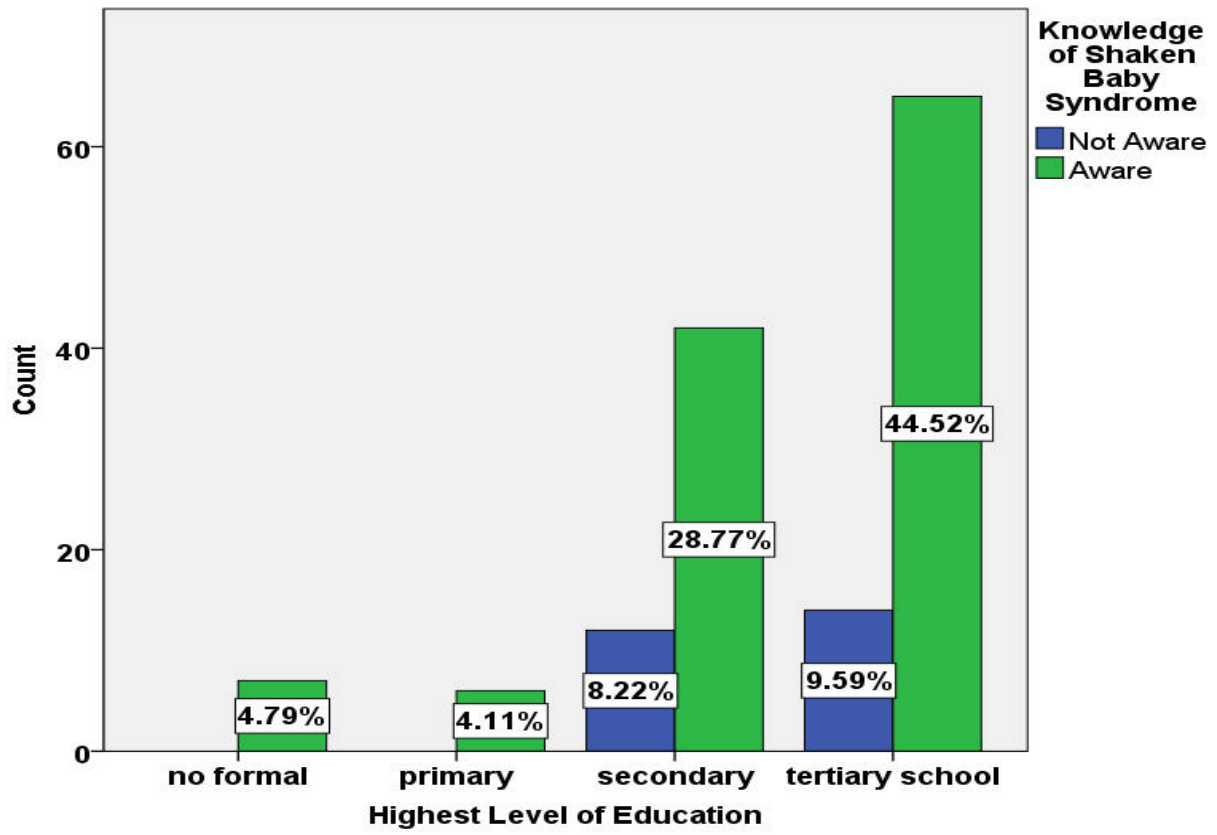

Figure 1: A clustered bar chart comparing the knowledge of Shaken Baby Syndrome (SBS) with level of education.

Note: 2 points was awarded to those that answered Yes and 1 point for No resulting to a maximum possible score of 16 and minimum score of 8 . Those that scored above 8 were said to be 'aware' of SBS while those that scored below it were tagged 'Not Aware'

The knowledge of SBS was highest among those whose highest education level was tertiary school (44.52\%), followed by secondary $(28.77 \%)$, no formal $(4.79 \%)$ and primary $(4.11 \%)$. Those with tertiary education also had the highest number of participants who are not aware of SBS.

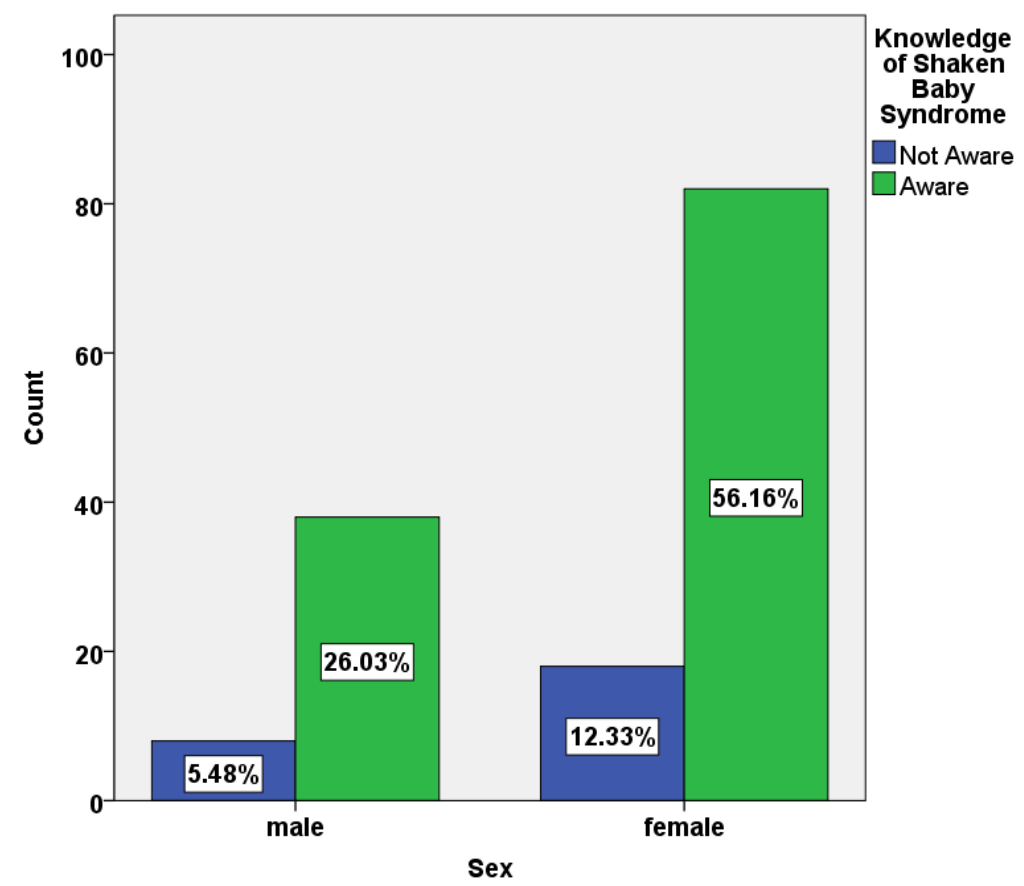

Figure 2: A clustered bar chart showing the knowledge of Shaken Baby Syndrome (SBS) among Male and 


\section{Female}

Note: 2 points was awarded to those that answered Yes and 1 point for No resulting to a maximum possible score of 16 and minimum score of 8 . Those that scored above 8 were

said to be 'aware' of SBS while those that scored below it were tagged 'Not Aware

From the chart, among female participants $12.33 \%$ were not aware of shaken baby syndrome while $56.16 \%$ had knowledge of SBS. Among the male participants, 5.48\% were not aware of SBS while 26.03\% were aware. Generally, females were more knowledgeable about SBS than male.

Table 4: Practice of Shaken Baby Syndrome

\begin{tabular}{|c|c|c|}
\hline Practice of Shaken Baby Syndrome & Yes & No \\
\hline Have you shaken your child violently on previous occasions? & $58(39.7 \%)$ & $88(60.3 \%)$ \\
\hline Do you shake your child when you want him/her to sleep? & $52(35.6 \%)$ & $94(64.4 \%)$ \\
\hline I shake my child but in a playful manner & $108(74.0 \%)$ & $38(26.0 \%)$ \\
\hline Do you shake your child when he/she cries too much? & $72(49.3 \%)$ & $74(50.7 \%)$ \\
\hline Do you shake your child when he/she annoys you? & $46(31.5 \%)$ & $100(68.5 \%)$ \\
\hline Do you shake your child when you want him/her to take a drug? & $26(17.8 \%)$ & $120(82.2 \%)$ \\
\hline Do you shake your child when you want to frighten him/her? & $52(35.6 \%)$ & $94(64.4 \%)$ \\
\hline Do you throw your baby up very high and catch him/her? & $83(56.8 \%)$ & $63(43.2 \%)$ \\
\hline Do you shake your child violently to wake them up from sleep? & $37(25.3 \%)$ & $109(74.7 \%)$ \\
\hline Do you leave your child on car seat without restraints in a moving car? & $26(17.8 \%)$ & $120(82.2 \%)$ \\
\hline Do you push your child violently away when they are disturbing you? & $48(32.9 \%)$ & $98(67.1 \%)$ \\
\hline
\end{tabular}

This table shows that $39.7 \%$ of participating caregivers have shaken their child violently on previous occasions. $35.6 \%$ shake their children when they want them to sleep, $74 \%$ shake their children in a playful manner, $56.8 \%$ throw up their children very high and catch them. Other wrong practices by participating caregivers leading to shaken baby syndrome are summarized in the table.

Table 5: A table showing the result of test of significance between wrong practices leading to Shaken Baby Syndrome and Marital status using Chi-square

\begin{tabular}{|c|c|c|c|c|c|c|}
\hline \multirow{2}{*}{$\begin{array}{l}\text { Practice of Shaken Baby } \\
\text { Syndrome }\end{array}$} & \multicolumn{3}{|c|}{ Marital Status } & \multirow[b]{2}{*}{ Total } & \multirow[b]{2}{*}{$\mathbf{X}^{2}$} & \multirow[b]{2}{*}{ P-VALUE } \\
\hline & Single & Married & Divorced & & & \\
\hline \multirow[t]{2}{*}{ No } & 1 & 1 & 0 & 2 & \multirow{6}{*}{0.353} & \multirow{6}{*}{0.838} \\
\hline & $50.0 \%$ & $50.0 \%$ & $0.0 \%$ & $100.0 \%$ & & \\
\hline \multirow[t]{2}{*}{ Yes } & 48 & 84 & 12 & 144 & & \\
\hline & $33.3 \%$ & $58.3 \%$ & $8.3 \%$ & $100.0 \%$ & & \\
\hline \multirow[t]{2}{*}{ Total } & 49 & 85 & 12 & 146 & & \\
\hline & $33.6 \%$ & $58.2 \%$ & $8.2 \%$ & $100.0 \%$ & & \\
\hline
\end{tabular}

At a Chi-Square value of $\mathbf{0 . 3 5 3}$, the p-value is $\mathbf{0 . 8 3 8}$ and since it is $>0.05$, there is no statistically significant difference between practice of Shaken Baby syndrome and marital status. 


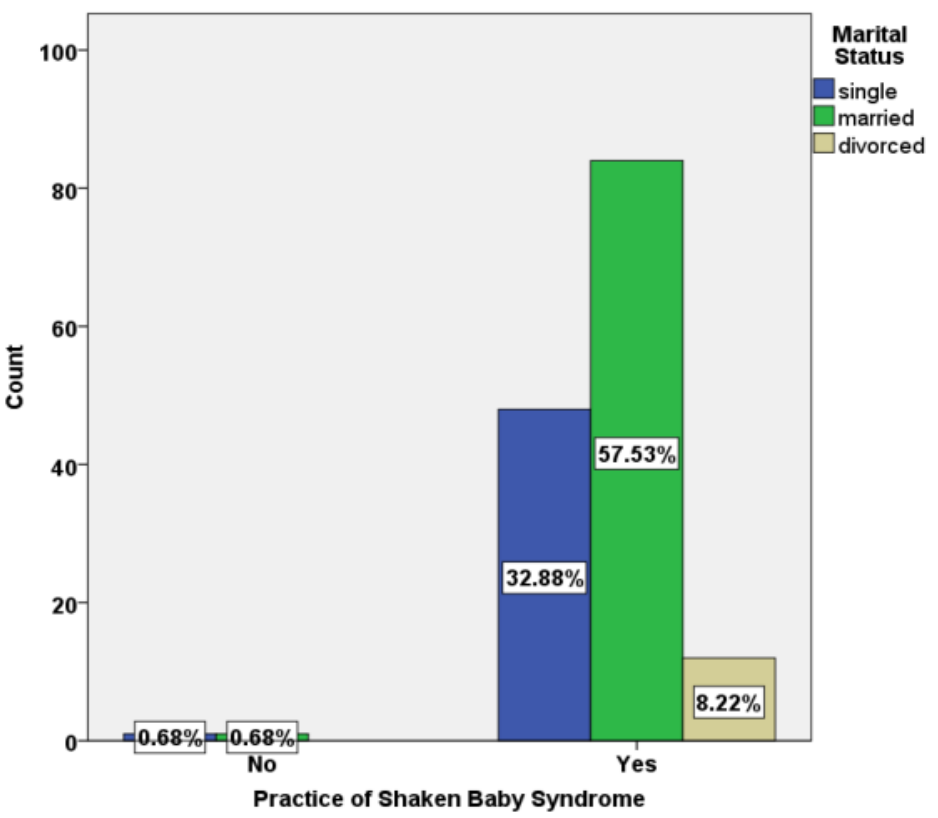

Figure 3: A clustered bar chart comparing practice of Shaken Baby Syndrome and marital status

The chart shows that a total of $98.63 \%$ engage in wrong practices that can lead to shaken baby syndrome. Among them, $57.73 \%$ were married, $32.88 \%$ were single and $8.22 \%$ were divorced. This difference between wrong practices leading to shaken baby syndrome and marital status was not statistically significant $\left(X^{2}=\mathbf{0 . 3 5 3 , p}=\boldsymbol{0 . 8 3 8}\right)$ using Chi-Square test

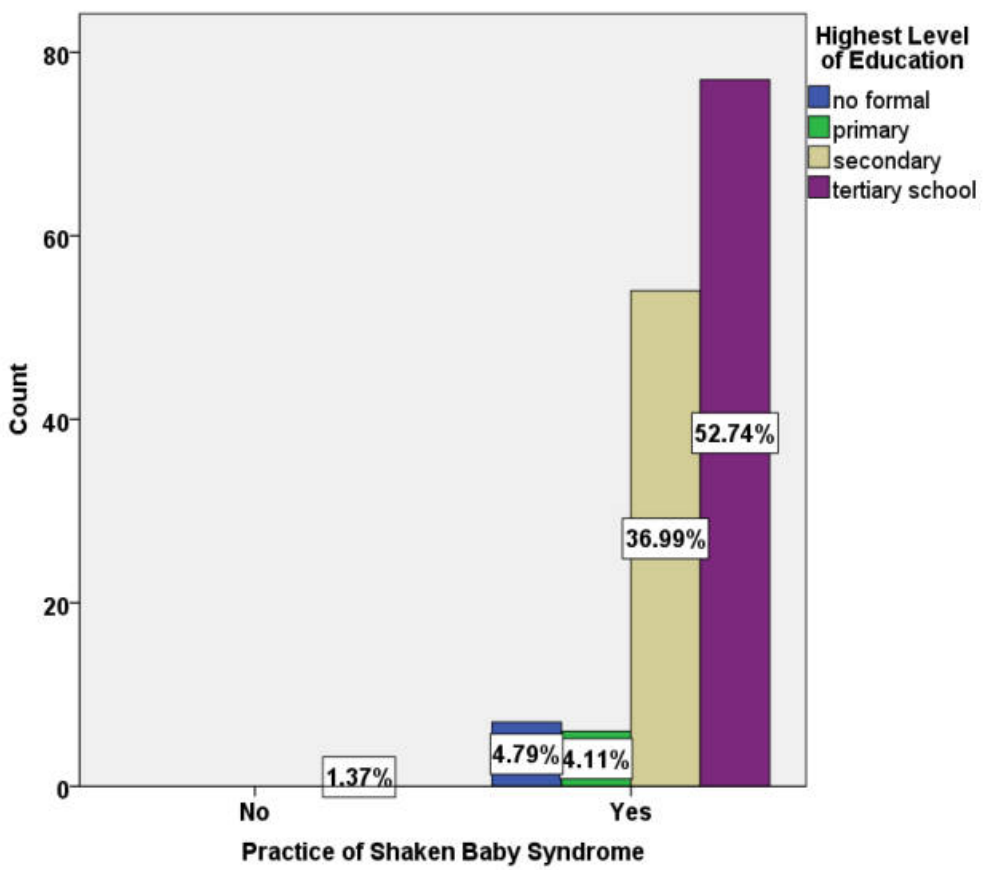

Figure 4: A clustered bar chart comparing practices leading to Shaken baby syndrome and highest of education 
The chart shows that among those with wrong practices that lead to shaken baby syndrome, $52.74 \%$ had tertiary education as their highest level of education, $36.99 \%$ secondary, $4.11 \%$ primary while $4.79 \%$ had no formal education. This difference between wrong practices leading to shaken baby syndrome and highest level of education was not statistically significant $\left(X^{2}=1.720, p=0.633\right)$ using Chi-Square test

\section{Discussion}

\section{Caregivers Knowledge of Shaken Baby Syndrome (SBS)}

The knowledge of Shaken Baby Syndrome was commendable in this study as shown in table 1.73.3\% of the participants knew about Shaken baby syndrome (SBS) among which 25.2\% got the knowledge from media, 24.3\% from internet and the rest were from Church, textbooks and other means. From this study, the knowledge of SBS was highest among those whose highest education level was tertiary school (44.52\%), followed by secondary $(28.77 \%)$, no formal $(4.79 \%)$ and primary $(4.11 \%)$. Those with tertiary education also had the highest number of participants who were not aware of SBS. No statistically significant association was seen between knowledge of shaken baby syndrome and highest level of education $\left(X^{2}=3.536, p=0.316\right)$

According to this study, females were more knowledgeable (56.16\%) about SBS than male (26.03\%). No statistically significant association was also seen between knowledge of Shaken Baby Syndrome and gender $\left(X^{2} 0.329, p=0.848\right)$, SBS and highest level of education $\left(X^{2} 12.551, p=0.316\right)$

\section{Assessment of wrong Practices by Caregivers Leading to Shaken Baby Syndrome}

This study (See Table 2 and Figure 1) shows that a total of $98.63 \%$ engage in wrong practices that can lead to shaken baby syndrome. Among them, $57.73 \%$ were married, $32.88 \%$ were single and $8.22 \%$ were divorced. This finding was contrary to a study conducted with 1,826 mothers who had babies aged three months in Holland, in which only $10 \%$ of the mothers reported that they used the methods of shaking or battering to silence their babies. ${ }^{[57}$, ${ }^{58,59]}$ A United State of America study ${ }^{[37,38,39]}$ reported that between $2.6 \%$ and $4.4 \%$ of the parents of children under 2 years of age had shaken their child at least once. In another study done in Brazil, 10\% of mothers who were interviewed reported having shaken their children younger than two years of age in the last one year. ${ }^{\text {[74] }}$

No statistically significant difference between wrong practices leading to Shaken baby syndrome and marital status $\left(X^{2}=0.353, p=0.838\right)$ using Chi-Square test.

Our study also showed (Table 2 and 3, Figure 2) that wrong practices that lead to shaken baby syndrome were not really affected by a person's highest level of education as it was seen more in those with tertiary education $52.74 \%$. This difference between wrong practices leading to shaken baby syndrome and highest level of education was not statistically significant $\left(X^{2}=1.720, p=0.633\right)$ using Chi-Square test.

\section{Conclusion}

The knowledge of Shaken Baby Syndrome was commendable in this study. No statistically significant association was seen between knowledge of Shaken Baby Syndrome and gender $\left(X^{2} \mathbf{0 . 3 2 9}, \boldsymbol{p}=\mathbf{0 . 8 4 8}\right)$, SBS and highest level of education $\left(X^{2} 12.551, p=0.316\right)$.

Wrong practices that can lead to SBS were also high $98.63 \%$ among our participating caregivers. There was no statistically significant difference between wrong practices leading to Shaken baby syndrome and marital status $\left(X^{2}=\mathbf{0 . 3 5 3}, p=0.838\right)$, practise of shaken Baby Syndrome and highest level of education $\left(X^{2}=1.720, p=0.633\right)$ using Chi-Square test 


\section{References}

1. Child Abuse Prevention Center. In Research Project on the Incidence and Risk Factors of Shaken Baby Syndrome in the State of Utah, Child Abuse Prevention Center, Ogden, Utah 1998, 1-18.

2. King WJ, MacKay M, Sirnick A, The Canadian Shaken Baby Study Group. In Shaken baby syndrome in Canada: Clinical characteristics and hospital outcomes of hospital cases, Canadian Medical Association [serial online] 2003, 168. Available from: www.cmaj.ca/search.dtl. Accessed April 10, 2003.

3. Bonnier C, Nassogne MC, Saint-Martin C, Mesples B, Kadhim H, Sébire G, et al. Neuroimaging of intraparenchymal lesions predicts outcome in shaken baby syndrome. Pediatric [PubMed] 2003; 112:80814.

4. Christian CW, Block R, the Committee on Child Abuse and Neglect Abusive head trauma in infants and children. Pediatrics [PubMed] 2009; 123:1409-11.

5. David TJ "Shaken baby (shaken impact) syndrome: non-accidental head injury in infancy". Journal of the Royal Society of medicine (November 1999). 92 (11):556-61. PMC 1297429. PMID 10703491

6. Integrity in Science: The Case of Dr Norman G, Dr Lynne Wrennall 'Shaken Baby Syndrome' and Miscarriages of Justice By Archived at the Wayback Achine2015-03-09.

7. Archived copy". Archived from the original on 2010-03-13. Retrieved 2011-04-30.

8. Caffey $\mathrm{J}$ "On the theory and practice of shaking infants. Its potential residual effects of permanent brain damage and mental retardation". American Journal of Diseases of Children (August 1972). 124 (2): $161-$ 9. doi: $10.1001 /$ archpedi.1972.02110140011001. PMID 4559532.

9. American Academy of Pediatrics: Committee on Child Abuse and Neglect "Shaken baby syndrome: rotational cranial injuries-technical report" Pediatrics(July 2001) 108 (1):206-10.

10. World Health Organization. World Report on Violence and Health. Geneva: WHO; 2002.

11. Reece RM, Sege R. Childhood head injury. Arch Pediatr Adolesc Med.[PubMed] 2009;154:11-15.

12. Salehi-Had H, Brandt JD, Rosas AJ, Rogers KK. Findings in older children with abusive head injury: Does shaken-child syndrome exist? Pediatrics. [PubMed] 2006; 117:e1039-44

13. Caffey J. On the theory and practice of shaking infants. Its potential residual effects of permanent brain damage and mental retardation. Am J Dis Child. [PubMed] 1972; 124:161-9.

14. King WJ, Mackay M, Sirnick A, Canadian Shaken Baby Study Group Shaken baby syndrome in Canada: Clinical characteristics and outcomes of hospital cases.[PubMed] 2003,CMAJ;168:155-9.

15. Morad Y, Kim YM, Armstrong DC, Huyer D, Main M, Levin AV. Correlation between retinal abnormalities and intracranial abnormalities in the shaken baby syndrome. Am J Opthalmol. [PubMed] 2002; $134: 354-9$

16. Case ME, Graham MA, Handy TC, Jentzen JM, Monteleone JA. National Association of Medical Examiners Ad Hoc Committee on Shaken Baby Syndrome. Position paper on fatal abusive head injuries in infants and young children. Am J Forensic Med Pathol. [PubMed] 2002;22:112-22.

17. Alexander R, Sato Y, Smith W, Bennet T. Incidence of impact trauma with cranial injuries ascribed to shaking. Am J Dis Child.[PubMed] 1990;144:724-6.

18. Talvik I, Alexander RC, Talvik T. Shaken baby syndrome and a baby's cry. Acta Paediatr [PubMed] 2008;97:782-5.

19. Barr RG, Trent RB, Cross J. Age-related incidence curve incidence curve of hospitalized shaken baby syndrome cases: Convergent evidence for crying as a trigger to shaking. Child Abuse Negl. [PubMed] 2006;30:7-16.

20. Reece RM, Kirschner RH. Shaken baby syndrome/shaken impact syndrome. The National Center on Shaken Baby Syndrome website, 1998. Available at: www. dontshake.com/ sbssummer 98 history.html. Accessed October 29, 2002.

21. Child Abuse Prevention Center. In Research Project on the Incidence and Risk Factors of Shaken Baby Syndrome in the State of Utah, Child Abuse Prevention Center, Ogden, Utah 1998, 1-18.

22. Schloff S, Mullaney PB, Armstrong DC, Simantirakis E, Humphreys RP, Myseros JS, et al. Retinal findings in children with intracranial hemorrhage Ophthalmology. [PubMed] 2002;109:1472-6.

23. U.S. Department of Health and Human Services Administration for Children and Families. National Child Abuse and Neglect Data System (NCANDS). Child Maltreatment 2000, U.S. Government Printing Office, Washington, DC 2002.

24. Bruce DA, Zimmerman RA. Shaken impact syndrome. Pediatr Ann 1989;18:484. 486-89,502,504.

25. The National Center on Shaken Baby Syndrome. Shaken baby syndrome fatalities in the United States, The National Center on Shaken Baby Syndrome, Ogden, Utah 1998.

26. Loh JK, Lin CL, Kwan AL, Howng SL. Acute subdural hematoma in infancy. Surg Neurol.[PubMed] 
2002;58:218-24

27. Wilkinson WS, Han DP, Rappley MD, Owings CL. Retinal hemorrhage predicts neurologic injury in the shaken baby syndrome. Arch Ophthalmol. [PubMed] 1989;107:1472-4.

28. Forbes BJ, Rubin SE, Margolin E, Levin AV. Evaluation and management of retinal hemorrhages in infants with and without abusive head trauma. J AAPOS.[PubMed] 1989;14:267-73.

29. Alexander RC, Sato Y, Smith W, Bennett T. Incidence of impact trauma with cranial injuries ascribed to shaking. Am J Dis Child [PubMed] 1990;144: 724-6.

30. Ewing-Cobbs L, Kramer L, Prasad M, et al. Neuroimaging, physical and developmental findings after inflicted and non-inflicted traumatic brain injury in young children. Pediatrics [PubMed] 1998;102: 300-7.

31. Kemp AM, Stoodley N, Cobley C, Coles L, Kemp KW. Apnoea and brain swelling in non-accidental head injury. Arch Dis Child [PMC free article] [PubMed] 2003;88: 472-6.

32. Jenny C, Hymel KP, Ritzen A, Reinart SE, Hay TC. Analysis of missed cases of abusive head trauma. JAMA [PubMed] 1999; 281: 621-6.

33. Reece RM, Sege R. Childhood head injuries: accidental or inflicted? Arch Pediatr Adolesc Med [PubMed] 2000;154: 11-5.

34. Duhaime AC, Alario AJ, Lewander WJ, Schut L, Sutton LN, et al. Head injury in very young children: mechanisms, injury types and ophthalmologic findings in 100 hospitalized patients younger than 2 years. Pediatrics [PubMed]1992;90: 179-85.

35. Levin A. Retinal haemorrhages and child abuse. Recent Advances in Paediatrics (TJ David, ed.) 2000;18: 151-219.

36. Feldman KW, Bethel R, Shugerman RP, Grossman DC, Ellenbogen RG, Grady MS. The cause of infant and toddler subdural hemorrhage: a prospective study. Pediatrics [PubMed] 2001; 108: 636-46.

37. Reynolds A. Shaken baby syndrome: diagnosis and treatment. Radiol Technol. [PubMed] 2008; 2008;80: 151-170.

38. Runyan DK. The challenges of assessing the incidence of inflicted traumatic brain injury: a world perspective. Am J Prev Med [PubMed] 2008;34:112-115.

39. Theodore AD, Chang JJ, Runyan DK, Hunter WM, Bangdiwala SI, Agans R. Epidemiologic features of the physical and sexual maltreatment of children in the Carolinas. Pediatrics [PubMed] 2005;115: e331-e337.

40. H. Selehl-Had, J.D. Brandt, A.J. Rosas, K.K. Rogers findings in older children with abusive head injury: event history analysis result Pediatrics, (2006) 117 , pp. 1039-1044.

41. S. Lazoritz, V.J. Palusci The shaken baby syndrome: a multidisciplinary approachThe Haworth Maltreatment \& Trauma Press, Binghamton (2001)

42. T.M. Kajese, L.T. Nguyen, G.Q. Pham, V.K. Pham, K. Melhorn, K.J. Kallail Characteristics of child abuse homicides in the state of Kansas from 1994 to 2007 Child Abuse Negl, (2011), 35 pp. 147-154

43. Center of Disease and Control. Child Maltreatment: Factsheet. Atlanta: National Center for Injury Prevention \& Control; 2007. [Cited 13 July 2010]

44. C. Jenny, K.P. Hymel, A. Ritzen, S.E.Reinert, T.C. Hay Analysis of missed cases of abusive head trauma JAMA, (1999), 290 pp. 621-626

45. T. Sieswerda -Hoogendoorn, S. Boos, B.Spivack, R.A.C. Blo, R.R. van Rijn Abusive head trauma - part I. Clinical aspectsEur J Pediatr, (2012), 171 pp. 415-423.

46. Case MD, editor. What does science tell us about abusive head trauma in infants and young children? Farmington: National Center on Shaken Baby Syndrome [cited 13 July 2010].

47. M.E. Case, M.A. Graham, T.C. Handy, J.M. Jentzen, J.A.MonteleonePosition paper on fatal abusive head injuries in infants and young children Am JForensic Med Pathol, (2001) 22 pp. 112-122

48. M. Fanconi, U. Lips Shaken baby syndrome in Switzerland: results of a prospective follow-up study, 20022007Eur J Pediatr, (2010) 169 , pp. 1023-1028

49. J. Friedman, P. Reed, P. Sharplin, P. Kelly Primary prevention of pediatric abusive head trauma: a cost audit and cost-utility analysisChild Abuse Negl, (2012), 36 pp. 760-770

50. Altman RL, Canter J, Patrick PA, Daley N, Butt NK, Brand DA. Parent education by maternity nurses and prevention of abusive head trauma. Pediatrics. 2011;128:e1164-72.

51. M.S. Dias, K. Smith, K. DeGuehery, P. Manzur, V. Li, M.L. Shaffer Preventing abusive head trauma among infants and young children: a hospital-based, parent education program Pediatrics, (2005) 115 pp. $470-477$

52. G. Deyo, T. Skybo, A. Carroll Secondary analysis of the "love me... never shake,e" SBS education programChild Abuse Negl, (2008) 32 , pp. 1017-1025

53. Deyo G, Skybo T, Carroll A. Secondary analysis of the "Love Me...Never Shake Me" SBS education 
program. Child Abuse Negl. [PubMed] 2008;32:1017

54. Goulet C, Frappier JY, Fortin S, Déziel L, Lampron A, Boulanger M. Development and evaluation of a shaken baby syndrome prevention program. J Obstet Gynecol Neonatal Nurs. [PubMed] 2009;38:7-21

55. ARCHI - Shaking Your Baby is Just Not the Deal [internette]. Erişim tarihi: Ocak 2013. Erişim:

56. Van der Wal MF, van den Boom DC, Pauw-Plomp H, de Jonge GA. Mothers' reports of infant crying and soothing in a multicultural population. Arch Dis Child.[PubMed]1998;79:312-7.

57. Carbaugh SF. Understanding shaken baby syndrome. Adv Neonatal Care. [PubMed] 2004;4: 105-14.

58. Overpeck MD, Brenner RA, Trumble AC, Trifiletti LB, Berendes HW. Risk factors for infant homicide in the United States. N Engl J Med. [PubMed] 1998; 339:1211-6.

59. Holden JR, Jenny C. Abusive head trauma: the relationship of perpetrators to their victims. Pediatrics [PubMed] 1995;95:259-62.

60. K.M. Barlow, R.A. Minns Annual incidence of shaken impact syndrome in young children Lancet, (2000) 356 pp. $1571-1572$

61. H. Keenan, D. Runyan Shaken baby syndrome: lethal inflicted traumatic brain injury in young childrenN C Med J, (2001) 62 pp. 345-348

62. H. Keenan, K. Runyan, S. Marshall, M. Nocera, D. Merten, S. SiSnala population - based study of Inflicted Traumatic Brain Injury in young children JAMA, (2003) 290 pp. 621-626

63. P. Kelly, B. Farrant Shaken baby syndrome in New Zeland, 2000-2002J Paediatr Child Health, (2008) 44, pp. $99-107$

64. S. Parks, D. Sugerman, L. Xu, V. Coronoado Characteristics of non-fatal abusive head trauma among children in the USA, 2003-2008: application of the CDC operational case definition to national hospital inpatient data Inj Prev, (2012) 18 pp. 392-398.

65. S.E. Parks, S.R. Kegler, J.L. Annest, J.A. Mercey Characteristics of fatal abusive head trauma among children in the USA: 2003-2007: an application of the CDC operational case definition to national vital statistics data Inj Prev, (2012) 18 pp. 193-199

66. World Health Organization International Society for Prevention of Child Abuse and Neglect. Preventing child maltreatment: a guide to taking action and generating evidence WHO Press, Genebra (2006)

67. K.W. Feldman, R. Bethel, R.P. Shugerman, D.C. Grossma n, M.S. Grady, R.G. Ellenbogen The cause of infant and toddler subdural hemorrhage: a prospective study Pediatrics, (2001) 108pp. 636-646

68. Selehl-Had H, Brandt JD, Rosas AJ, Rogers KK. indings in older children with abusive head injury: event history analysis result. Pediatrics 2006; 117:1039-44.

69. A.D. Theodore, D.K. Runyan A survey of pediatricians' attitudes and experiences with court in cases of child maltreatment Child Abuse Negl, 30 (2006), pp. 1353-1363

70. Theodore AD, Chang JJ, Runyan DK, Hunter WM, Bangdiwala SI, Agans R. Epidemiologic features of the physical and sexual maltreatment of children in the Carolinas.[PubMed] Pediatrics 2005;115:e331-7

71. Reijneveld SA, van der Wal MF, Brugman E, Sing RA, Verloove-Vanhorick SP. Infant crying and abuse. Pediatrics [PubMed] 2004; 364: 1340 -2. [Ref list]

72. Vinchon M, the Foort Dhellemmes S, D,esurmont M, Delestret . Confessed abuse versus witnessed accidents in infants: comparison of clinical, radio- logical, and ophthalmological data into corroborated cases. Childs serv 'syst 2010; 26:637 45.

73. Adamsbaum C, Grabar S, Mejean N, ReySalmon c. Abusive head trauma: judicial admissions highlight violent and repetitivee shaking. Pediatrics 2010; 126:546 55.

74. D.K. Runyan, V. Shankar, F. Hassan, W.M. Hunter, D. Jaind, C.D.Paula, et al. International variations in harsh child disciplinePediatrics(2010), 126 pp. e701-e711

75. Reijneveld SA, van der Wal MF, Brugman E, Hira Sing RA, Verloove-Vanhorick SP. Prevalence of parental behaviour to diminish the crying of infants that may lead to abuse. Ned TijschrGeneeskd. [PubMed] 2004; 148:2227-30

76. V.M. Fernandes, N.L. Silva, M. Javorski Prevenção da Síndrome do Bebê Sacudido: conhecimento da equipe de Saúde da Família Nursing, (2010) 13 , pp. 304-308

77. Dias MS, Smith K, DeGuehery K, Mazur P, Li V, Shaffer ML. Preventing abusive head trauma among infants and children: young a hospital-based, parenteducationprogram. Pediatrics [PubMed] 2005;115:e4707.

78. National Center on Shaken Baby Syndrome [internette]. Erişim tarihi: Haziran 2013.

79. Barr RG, Trent RB, Cross J. Age-related incidence curve of hospitalized Shaken Baby Syndrome cases: convergent evidence for crying as a trigger to shaking. Child Abuse Negl.[PubMed] 2006;30:7-16. 